\title{
Porcine Epidemic Diarrhea Virus and Discovery of a Recombinant Swine Enteric Coronavirus, Italy
}

\section{Beatrice Boniotti, ${ }^{1}$ Alice Papetti, ${ }^{1}$ Antonio Lavazza, Giovanni Alborali, Enrica Sozzi, Chiara Chiapponi, Silvia Faccini, Paolo Bonilauri, Paolo Cordioli, ${ }^{2}$ Douglas Marthaler}

Porcine epidemic diarrhea virus (PEDV) has been detected sporadically in Italy since the 1990s. We report the phylogenetic relationship of swine enteric coronaviruses collected in Italy during 2007-2014 and identify a drastic shift in PEDV strain variability and a new swine enteric coronavirus generated by recombination of transmissible gastroenteritis virus and PEDV.

$P$ orcine epidemic diarrhea virus (PEDV) and Transmissible gastroenteritis virus (TGEV) (family Coronaviridae, genus Alphacoronavirus) are enveloped viruses that contain a single-stranded, positive-sense RNA genome of $\approx 28 \mathrm{~kb}$. Infection with these viruses causes watery diarrhea, dehydration, and a high mortality rate among suckling pigs. Coronaviruses (CoVs) are prone to genetic evolution through accumulation of point mutations and homologous recombination among members of the same genus (1). Porcine respiratory coronavirus (PRCV), a mutant of TGEV, appeared in pigs in the 1980s (2). The spread of PRCV, which conserved most of the antigenic sites and causes cross-protection against TGEV (3), led to the gradual disappearance of TGEV. Newly emerging CoVs pose a potential threat to human and animal health because multiple human $\mathrm{CoV}$ infections have been derived from animal hosts. Emerging swine coronaviruses are of great concern to swine health because of the potential increase in viral pathogenesis.

In 1978, PEDV was first identified in Europe; subsequent reports occurred in many countries in Asia, including China, Japan, Korea, and Thailand. In 2010-2012, genetically different PEDV strains emerged, causing severe outbreaks in China (4). PEDV spread to the United States, Canada, and Mexico in 2013-2014, and genetically

Author affiliations: Istituto Zooprofilattico Sperimentale della Lombardia ed Emilia Romagna, Brescia, Italy (M.B. Boniotti,

A. Papetti, A. Lavazza, G. Alborali, E. Sozzi, C. Chiapponi,

S. Faccini, P. Bonilauri, P. Cordioli); University of Minnesota Veterinary Diagnostic Laboratory, St. Paul, Minnesota, USA (D. Marthaler)

DOI: http://dx.doi.org/10.3201/eid2201.150544 related strains were detected in South Korea and Taiwan (5-7). The PEDV outbreak caused large global economic losses to the swine industry. In Europe, a severe PEDV epidemic occurred in Italy during 2005-2006 (8), and in 2014-2015, PEDV was detected in Germany, France, and Belgium. These strains have a high nucleotide identity to PEDV strains that contain distinct insertions and deletions (INDELs) in the $\mathrm{S}$ gene (S-INDELs) from the United States (9-11). We report the detection and genetic characterization of swine enteric CoVs circulating in Italy during 2007-2014. We also report a recombinant TGEV and PEDV strain (identified as the species Swine enteric coronavirus [SeCoV]) circulating from June 2009 through 2012. Finally, we describe the phylogenetic relationship of the 2014 PEDV S-INDELs to the recent PEDV strains circulating in Europe.

\section{The Study}

During 2007-2014, we collected 27 fecal and 24 intestinal samples from pigs with suspected PEDV or TGEV infections; the pigs came from swine farms in northern Italy (Po Valley), which contains the regions of Piemonte, Lombardia, Emilia Romagna, and Veneto (online Technical Appendix Figure 1, http://wwwnc.cdc.gov/EID/ article/22/1/15-0544-Techapp1.pdf). The Po Valley contains $70 \%$ of Italy's swine. Clinical signs included watery diarrhea in sows and a death rate in piglets of $5 \%-10 \%$, lower than is typical with PEDV or TGEV infections. Samples were submitted for testing by electron microscopy, PEDV ELISA, viral isolation, pan-CoV reverse transcription PCR (RT-PCR), and RT-PCR for PRCV and TGEV; selected positive pan-CoV samples were sequenced (1214) (online Technical Appendix).

Results of electron microscopy showed that 25 (49\%) of the 51 samples contained CoV-like particles, but all samples were negative for viral isolation. Although only 38 samples $(74 \%)$ were positive by pan-CoV RT-PCR, $47(92 \%)$ were positive by the PEDV ELISA (Table 1) $(12,13)$. Of the 38 pan-CoV-positive samples, 18 were selected for partial RNA-dependent RNA polymerase (RdRp), spike (S1) (14), and membrane (M) sequencing (Table 1). All samples were negative for PRCV and TGEV by RT-PCR, ruling out co-infection with PEDV and TGEV or PRCV (15).

\footnotetext{
${ }^{1}$ These first authors contributed equally to this article.

${ }^{2}$ Deceased.
} 
Table 1. Distribution of test results of samples from pig farms in study of swine enteric coronaviruses in northern Italy, 2007-2014*

\begin{tabular}{|c|c|c|c|c|c|c|c|c|c|c|}
\hline \multirow{2}{*}{$\begin{array}{l}\text { Sample } \\
\text { no. }\end{array}$} & \multirow{2}{*}{$\begin{array}{c}\text { Farm } \\
\text { no. }\end{array}$} & \multirow[b]{2}{*}{ Year } & \multirow[b]{2}{*}{ Region } & \multirow[b]{2}{*}{ EM } & \multirow{2}{*}{$\begin{array}{l}\text { PEDV } \\
\text { ELISA }\end{array}$} & \multirow{2}{*}{$\begin{array}{l}\text { Pan-CoV } \\
\text { RT-PCR }\end{array}$} & \multirow{2}{*}{$\begin{array}{c}\text { TGEV/ } \\
\text { PRCV S1 }\end{array}$} & \multicolumn{3}{|c|}{ Sequences } \\
\hline & & & & & & & & $\mathrm{RdRp}$ & S1 & $\mathrm{M}$ \\
\hline 222654 & 1 & 2007 & Emilia Romagna & - & + & + & NA & NA & NA & NA \\
\hline 1448 & 2 & 2007 & Emilia Romagna & - & + & - & NA & NA & NA & NA \\
\hline 19908 & 3 & 2007 & Emilia Romagna & - & + & + & - & Cluster I & Cluster I & Cluster I \\
\hline 70323 & 4 & 2007 & Lombardia & + & + & + & NA & NA & $\dagger$ & NA \\
\hline 114372 & 5 & 2007 & Lombardia & + & + & + & NA & NA & NA & NA \\
\hline 200079 & 6 & 2007 & Lombardia & - & + & + & NA & NA & $\dagger$ & NA \\
\hline $320855 / 5$ & 7 & 2007 & Lombardia & + & + & + & - & Cluster I & Cluster I & Cluster I \\
\hline $320855 / 6$ & 7 & 2007 & Lombardia & + & + & + & NA & $\dagger$ & $\dagger$ & NA \\
\hline $3936 / 1$ & 8 & 2008 & Lombardia & - & + & + & - & Cluster I & Cluster I & Cluster I \\
\hline $3936 / 2$ & 8 & 2008 & Lombardia & - & + & + & NA & $\dagger$ & NA & NA \\
\hline 29177 & 9 & 2008 & Veneto & + & + & + & - & Cluster I & Cluster I & Cluster I \\
\hline 43853 & 10 & 2008 & Lombardia & + & + & - & NA & NA & NA & NA \\
\hline 7239‡ & 11 & 2009 & Lombardia & - & + & + & - & Cluster I & Cluster I & Cluster I \\
\hline 20001 & 12 & 2009 & Lombardia & - & + & + & - & Cluster I & Cluster I & Cluster I \\
\hline 20416 & 13 & 2009 & Lombardia & - & + & + & NA & $\dagger$ & $\dagger$ & NA \\
\hline 22603 & 14 & 2009 & Lombardia & - & + & + & - & Cluster I & Cluster I & Cluster I \\
\hline $26199 / 2$ & 15 & 2009 & Lombardia & - & + & - & NA & NA & NA & NA \\
\hline 87565 & 16 & 2009 & Emilia Romagna & - & + & + & NA & NA & $\dagger$ & NA \\
\hline $111357 / 7$ & 17 & 2009 & Lombardia & NA & + & - & NA & NA & NA & NA \\
\hline 137442 & 18 & 2009 & Lombardia & + & + & + & - & Cluster II & Cluster II & Cluster II \\
\hline 205396 & 19 & 2009 & Lombardia & + & + & - & NA & NA & NA & NA \\
\hline 208995 & 20 & 2009 & Lombardia & + & - & + & NA & $\dagger$ & NA & NA \\
\hline 213306‡ & 21 & 2009 & Lombardia & + & + & + & - & Cluster II & Cluster II & Cluster II \\
\hline 244945 & 22 & 2009 & Emilia Romagna & + & + & - & NA & NA & NA & NA \\
\hline 245242 & 22 & 2009 & Emilia Romagna & + & + & + & NA & $\dagger$ & NA & NA \\
\hline 274771 & 23 & 2009 & Veneto & + & - & - & NA & NA & NA & NA \\
\hline 307121 & 24 & 2009 & Emilia Romagna & + & + & + & - & Cluster II & Cluster II & Cluster II \\
\hline 315994 & 25 & 2009 & Lombardia & + & - & - & NA & NA & NA & NA \\
\hline 320695 & 26 & 2009 & Lombardia & + & + & + & NA & NA & $\dagger$ & $\dagger$ \\
\hline 320825 & 26 & 2009 & Lombardia & + & + & + & - & Cluster II & Cluster II & Cluster II \\
\hline 324345 & 27 & 2009 & Lombardia & + & + & + & NA & $\dagger$ & $\dagger$ & $\dagger$ \\
\hline 324374 & 27 & 2009 & Lombardia & + & + & + & NA & $\dagger$ & $t$ & $\dagger$ \\
\hline 324397 & 27 & 2009 & Lombardia & + & + & + & - & Cluster II & Cluster II & Cluster II \\
\hline $324507 / 1$ & 28 & 2010 & Lombardia & + & + & + & - & Cluster II & Cluster II & Cluster II \\
\hline $324507 / 2$ & 28 & 2010 & Lombardia & + & + & + & NA & NA & $\dagger$ & $\dagger$ \\
\hline $324507 / 3$ & 28 & 2010 & Lombardia & + & + & + & NA & NA & NA & $\dagger$ \\
\hline $324507 / 4$ & 28 & 2010 & Lombardia & + & + & + & NA & NA & $\dagger$ & $\dagger$ \\
\hline $5448 / 2$ & 29 & 2011 & Emilia Romagna & NA & + & - & NA & NA & NA & NA \\
\hline 28607 & 30 & 2012 & Lombardia & - & + & + & NA & NA & $\dagger$ & $\dagger$ \\
\hline 29742 & 30 & 2012 & Lombardia & + & + & + & - & Cluster II & Cluster II & Cluster II \\
\hline 30917 & 31 & 2012 & Lombardia & + & + & - & NA & NA & NA & NA \\
\hline $35621 / 1$ & 32 & 2012 & Lombardia & + & + & - & NA & NA & NA & NA \\
\hline $35621 / 2$ & 32 & 2012 & Lombardia & - & + & + & NA & NA & NA & NA \\
\hline 41906 & 33 & 2012 & Lombardia & - & + & + & NA & NA & NA & NA \\
\hline 44833 & 34 & 2012 & Lombardia & NA & + & + & - & Cluster II & Cluster II & Cluster II \\
\hline 67322 & 8 & 2012 & Lombardia & - & + & + & NA & NA & NA & $\dagger$ \\
\hline 273992 & 35 & 2012 & Lombardia & - & + & + & - & Cluster II & Cluster II & Cluster II \\
\hline 32961 & 36 & 2013 & Piemonte & - & + & - & NA & NA & NA & NA \\
\hline 32963 & 36 & 2013 & Piemonte & + & + & - & NA & NA & NA & NA \\
\hline 178509 & 37 & 2014 & Emilia Romagna & NA & NA & + & - & Cluster III & Cluster III & Cluster III \\
\hline 200885 & 38 & 2014 & Emilia Romagna & + & + & + & - & Cluster III & Cluster III & Cluster III \\
\hline $\begin{array}{l}{ }^{*} \text { Cluster I re } \\
\text { represents } \\
\text { porcine epi } \\
\text { gastroenter } \\
\text { †Sequence } \\
\text { †Samples s }\end{array}$ & fo & tive:- & $\begin{array}{l}\text { ative; NA, not testec } \\
\text { this study. }\end{array}$ & 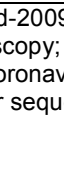 & ed. & 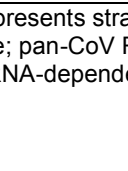 & NA & $\mathrm{s} 1 \mathrm{cn}$ & ough 2012; a & $\begin{array}{l}\text { cluster III } \\
\text { CR; PEDV, } \\
\text { sible }\end{array}$ \\
\hline
\end{tabular}

On the basis of the partial sequences from RdRp and the $\mathrm{S} 1$ and $\mathrm{M}$ genes, the strains from Italy clustered into 3 temporally divided groups, suggesting 3 independent virus entries. Cluster I represents strains circulating from 2007 through mid-2009; cluster II represents strains circulating from mid-2009 through 2012; and cluster III represents strains circulating since 2014 (online Technical Appendix Figure 2, panels A-C). Cluster I was identified in Emilia Romagna $(n=1)$, Lombardia $(n=5)$, and Veneto $(n=1)$. Cluster II was identified in Emilia Romagna $(\mathrm{n}=1)$ and Lombardia $(n=8)$. Cluster III was identified in Emilia Romagna at 2 swine farms. To help explain the temporal clustering, a 
single S1 gene segment was sequenced from clusters I and II (PEDV/Italy/7239/2009 and SeCoV/Italy/213306/2009, respectively). Because of the recent outbreak of PEDV in Europe, the 2 positive samples from cluster III (PEDV/ Italy/178509/2014 and PEDV/Italy/200885/2014) were sequenced (Figure 1, panel A).

One strain from each cluster was selected for whole genome sequencing (online Technical Appendix). Unfortunately, the whole genome was obtained from only clusters I and II (PEDV/Italy/7239/2009 and SeCoV/Ita1y/213306/2009, respectively; Figure 1, panel B). Recombination analysis was conducted on the 2 whole genomes and was not detected in PEDV/Italy/7239/2009. Recombination was detected in SeCoV/Italy/213306/2009 at position 20636 and 24867 of PEDV CV777 and at position 20366 and 24996 of TGEV H16 (Figure 2), suggesting the occurrence of a recombination event between a PEDV and a TGEV. The complete $\mathrm{S}$ gene of SeCoV/Italy/213306/2009 shared $92 \%$ and $90 \%$ nt identity with the prototype European strain PEDV CV777 and the original highly virulent North American strain Colorado 2013, respectively, and the remaining genome shared a $97 \%$ nt identity with the virulent strains TGEV H16 and TGEV Miller M6. Wholegenome analysis of PEDV/Italy/7239/2009 showed that it grouped with the global PEDV strains ( 6 ) and shared $\approx 97 \%$ nt identity with PEDV strains CV777, DR13 virulent, and North American S-INDEL strain OH851 (Table 2).

\section{Conclusions}

During 2007-2014, most (92\%) samples collected from the Po Valley in Italy were positive for PEDV by ELISA; only $72 \%$ were positive by pan-CoV PCR. However, because we were investigating the presence of PEDV or TGEV in samples with clinical signs of diarrhea, the high occurrence of PEDV may not reflect the actual prevalence of PEDV in Italy. The increased percentage
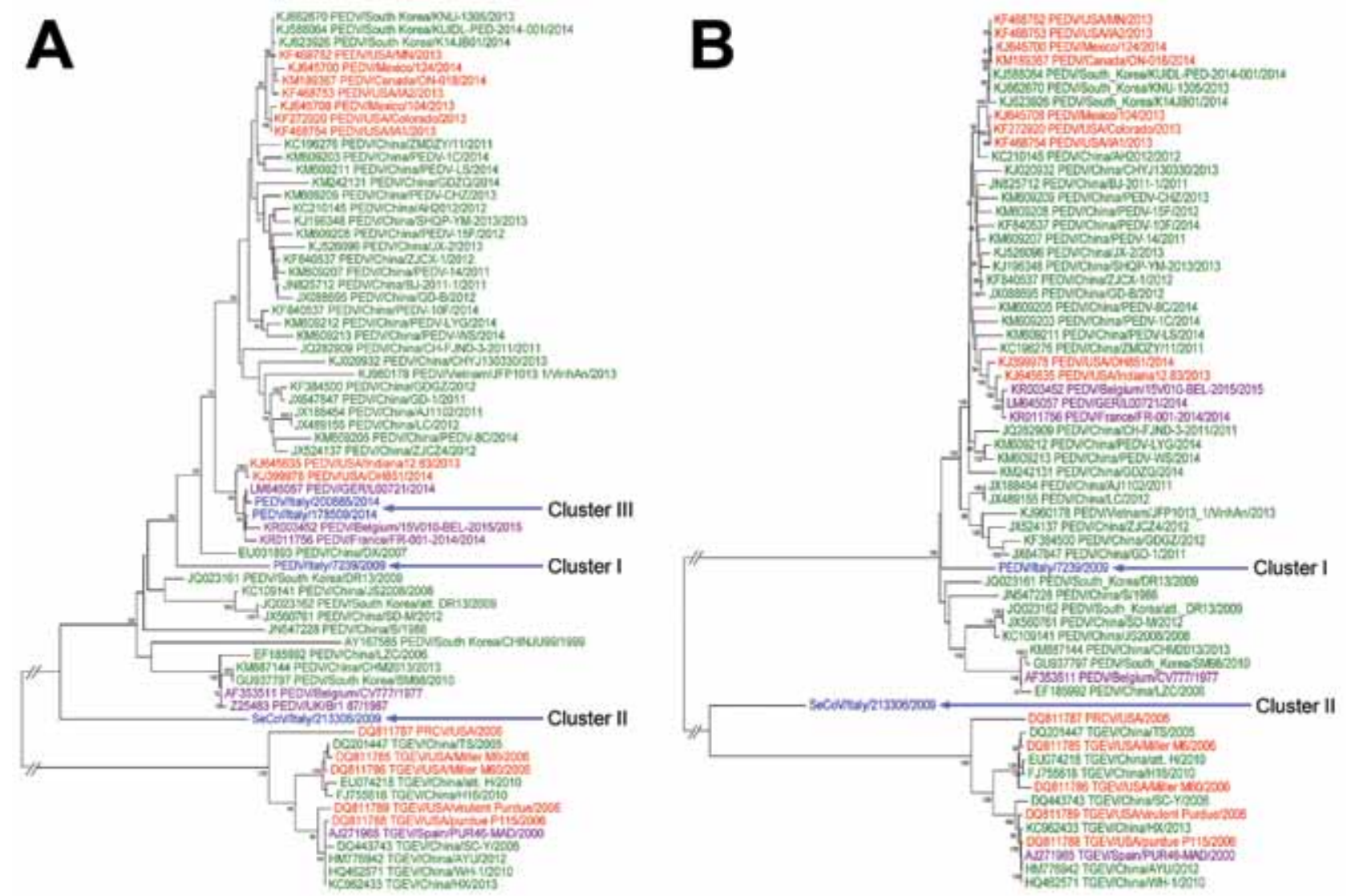

Figure 1. Phylogenetic analyses of swine enteric coronaviruses in Italy. A) Analysis performed on the basis of the nucleotide sequence of the complete spike (S1) gene of 4 representative strains from the 3 clusters and B) whole genome of 2 positive strains from clusters I and II. Cluster I represents strains circulating from 2007 through mid-2009; cluster II represents strains circulating from mid-2009 through 2012; and cluster III represents strains circulating since 2014. Bootstrap values $>70 \%(1,000$ replicates $)$ are indicated. Reference sequences are identified by GenBank accession no. and strain name. The strains from this study are represented in blue; strains from China are green; strains from North America are red; and strains from Europe are purple. PEDV, porcine epidemic diarrhea virus; PRCV, porcine respiratory coronavirus; TGEV, transmissible gastroenteritis virus; SeCoV, swine enteric coronavirus. 


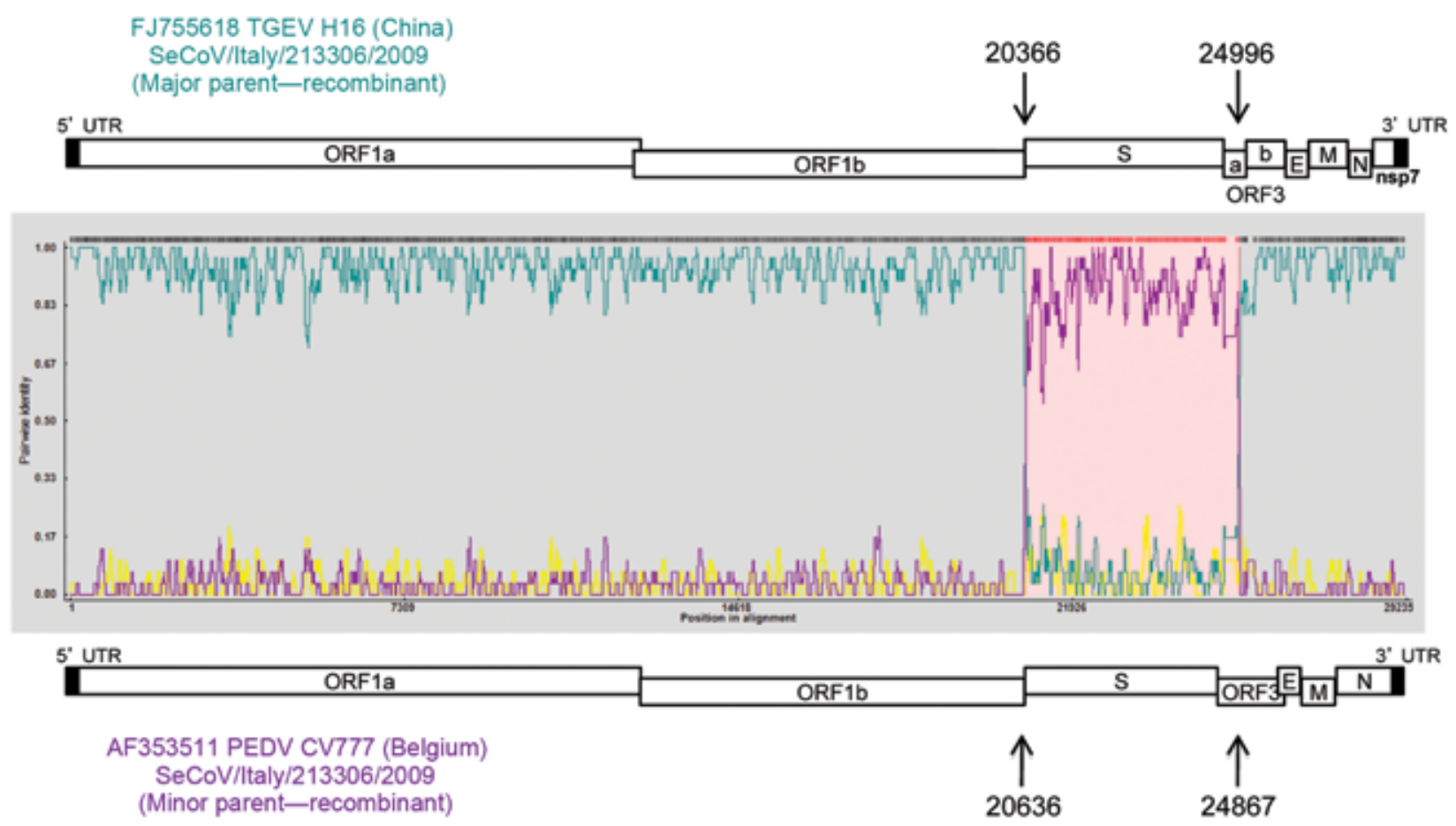

Figure 2. Potential recombination points in the SeCoV strains in study of swine enteric coronaviruses in Italy. The potential parent strains H16 (TGEV) and CV777 (PEDV) are shown in teal and purple, respectively. Arrows indicate recombinant breakpoints. UTR, untranslated region; ORF, openreading frame; S, spike; E, envelope; M, membrane; N, nucleocapsid; nsp, nonstructural protein; PEDV, porcine epidemic diarrhea virus; TGEV, transmissible gastroenteritis virus; SeCoV, swine enteric coronavirus.

of PEDV found in samples tested by ELISA, compared with the proportion found by PCR, may be explained by the number of ambiguous bases in the pan-CoV primers; the ambiguous bases severely reduce the efficiency of the reaction. The swine enteric $\mathrm{CoV}$ strains from Italy in our study, including the recombinant strain, were reported in pigs with mild clinical signs, indicating that PEDV and SeCoV have been circulating in Italy and likely throughout Europe for multiple years but were underestimated as a mild form of diarrhea.

To understand the evolution of PEDV in Italy, the partial RdRp, S, and M genes were sequenced from 18 samples and grouped in 3 different temporal clusters. Cluster I (2007-mid 2009) resembles the oldest PEDV strains; cluster II resembles a new TGEV and PEDV recombinant variant; and cluster III, identified from 2 pig farms in northern Italy in 2014, resembles the PEDV S-INDEL strains identified in Germany, France, Belgium, and the United States. The $>99.3 \%$ nt identity of the S1 gene within cluster III and in previously identified strains could suggest the spread of the S-INDEL strain into Europe. However, directionality of spread cannot be determined because of a lack of global and temporal PEDV sequences.

Although our findings could indicate 3 introductions of PEDV in Italy, the results more likely suggest the high ability of natural recombination among CoVs and the

Table 2. Nucleotide identities of strains PEDV/Italy/7239/2009 and SeCoV/Italy/213306/2009, representative of clusters I and II, respectively, in study of swine enteric coronaviruses in Italy*

\begin{tabular}{|c|c|c|c|c|c|c|c|c|c|c|c|c|}
\hline \multirow[b]{2}{*}{ Strain identification } & \multicolumn{2}{|c|}{ ORF1 } & \multicolumn{2}{|c|}{ Spike } & \multicolumn{2}{|c|}{ ORF3 } & \multicolumn{2}{|c|}{ Envelope } & \multicolumn{2}{|c|}{ Membrane } & \multicolumn{2}{|c|}{ Nucleocapsid } \\
\hline & $\mathrm{I}$ & II & $\mathrm{I}$ & II & 1 & II & 1 & II & 1 & II & 1 & II \\
\hline PEDV/Belgium/CV777/1977 & 97.3 & 57.8 & 96.3 & 92.7 & 98.1 & 43.6 & 97.6 & 43.0 & 97.6 & 55.9 & 96.6 & 42.5 \\
\hline PEDV/South Korea/DR13 vir/2009 & 98.1 & 58.0 & 97.3 & 93.1 & 99.3 & 43.7 & 99.6 & 43.0 & 97.7 & 55.6 & 97.6 & 43.3 \\
\hline PEDV/USA/Colorado/2013 & 98.0 & 57.9 & 94.6 & 90.7 & 98.6 & 44.0 & 99.2 & 43.0 & 97.8 & 55.3 & 96.8 & 43.4 \\
\hline PEDV/USA/OH851/2014 & 98.1 & 57.9 & 96.9 & 91.9 & 98.7 & 43.8 & 99.2 & 43.0 & 97.7 & 55.5 & 96.7 & 43.4 \\
\hline PEDV/L00721/GER/2014 & 98.0 & 57.9 & 97.0 & 92.0 & 98.6 & 43.7 & 99.2 & 43.0 & 97.8 & 55.3 & 96.8 & 43.4 \\
\hline TGEV/USA/Miller M6/2006 & 57.9 & 96.8 & 52.0 & 52.5 & 40.0 & 89.1 & 42.6 & 96.4 & 56.1 & 97.1 & 43.1 & 96.3 \\
\hline PRCV/USA/ISU-1/2006 & 58.0 & 96.5 & 47.7 & 48.2 & 53.0 & 76.6 & 43.8 & 96.0 & 56.2 & 96.3 & 42.8 & 95.7 \\
\hline
\end{tabular}

*Cluster I represents strains circulating from 2007 through mid-2009; cluster II represents strains circulating from mid-2009 through 2012.6 ORF, open reading frame; PRCV, porcine respiratory coronavirus; PEDV, porcine epidemic diarrhea virus; SeCoV, swine enteric coronavirus; TGEV, transmissible gastroenteritis virus. 
continued emergence of novel CoVs with distinct pathogenic properties. Further investigation is needed to determine the ancestor of the $\mathrm{SeCoV}$ strain or to verify whether the recombinant virus was introduced in Italy. Recombinant $\mathrm{SeCoV}$ was probably generated in a country in which both PEDV and TGEV are endemic, but because the presence of these viruses in Europe is unclear and $\mathrm{SeCoV}$ has not been previously described, it is difficult to determine the parental strains and geographic spread of SeCoV. Future studies are required to describe the pathogenesis of $\mathrm{SeCoV}$ and its prevalence in other countries.

This work was funded by the Italian Ministry of Health (project PRC2010010- E87G11000130001).

Dr. Boniotti is a scientist at the Istituto Zooprofilattico Sperimentale della Lombardia e Emilia Romagna; her primary research interests include molecular diagnosis and epidemiology of viral and bacterial infectious diseases. Dr. Papetti is a research scientist at the Istituto Zooprofilattico Sperimentale della Lombardia e Emilia Romagna; her major research interests are molecular diagnostic development and phylogenetic analysis of infectious diseases.

\section{References}

1. Enjuanes L, Brian D, Cavanagh D, Holmes K, Lai MMC, Laude H, et al. Coronaviridae. In: van Regenmortel MHV, Fauquet CM, Bishop DHL, Carstens EB, Estes MK, Lemon SM, et al., editors. Virus taxonomy. Classification and nomenclature of viruses. New York: Academic Press; 2000. p. 835-9.

2. Pensaert M, Callebaut $P$, Vergote J. Isolation of a porcine respiratory, non-enteric coronavirus related to transmissible gastroenteritis. Vet Q. 1986;8:257-61. http://dx.doi.org/10.1080/01652176.1986.9694050

3. Wesley RD, Woods RD. Immunization of pregnant gilts with PRCV induces lactogenic immunity for protection of nursing piglets from challenge with TGEV. Vet Microbiol. 1993;38:31-40. http://dx.doi.org/10.1016/0378-1135(93)90073-G

4. Huang YW, Dickerman AW, Pyñeyro P, Li L, Fang L, Kiehne R, et al. Origin, evolution, and genotyping of emergent porcine epidemic diarrhea virus strains in the United States. mBiol. 2013; 4:00737-13. http://dx.doi.org/10.1128/mBio.00737-13

5. Stevenson GW, Hoang H, Schwartz KJ, Burrough ER, Sun D, Madson D, et al. Emergence of porcine epidemic diarrhea virus in the United States: clinical signs, lesions, and viral genomic sequences. J Vet Diagn Invest. 2013;25:649-54. http://dx.doi.org/ $10.1177 / 1040638713501675$
6. Vlasova AN, Marthaler D, Wang Q, Culhane MR, Rossow KD, Rovira A, et al. Distinct characteristics and complex evolution of PEDV strains, North America, May 2013-February 2014. Emerg Infect Dis. 2014;20:1620-8. http://dx.doi.org/10.3201/ eid2010.140491

7. Sun M, Ma J, Wang Y, Wang M, Song W, Zhang W, et al. Genomic and epidemiological characteristics provide new insights into the phylogeographical and spatiotemporal spread of porcine epidemic diarrhea virus in Asia. J Clin Microbiol. 2015;53:148492. http://dx.doi.org/10.1128/JCM.02898-14

8. Martelli P, Lavazza A, Nigrelli AD, Merialdi G, Alborali LG, Pensaert MB. Epidemic of diarrhoea caused by porcine epidemic diarrhoea virus in Italy. Vet Rec. 2008;162:307-10.

http://dx.doi.org/10.1136/vr.162.10.307

9. Hanke D, Jenckel M, Petrov A, Ritzmann M, Stadler J, Akimkin V, et al. Comparison of porcine epidemic diarrhea viruses from Germany and the United States, 2014. Emerg Infect Dis. 2015;21:493-6. http://dx.doi.org/10.3201/eid2103.141165

10. Grasland B, Bigault L, Bernard C, Quenault H, Toulouse O, Fablet $\mathrm{C}$, et al. Complete genome sequence of a porcine epidemic diarrhea $\mathrm{S}$ gene indel strain isolated in France in December 2014. Genome Announc. 2015;3:e0535-15. http://dx.doi.org/10.1128/ genomeA.00535-15

11. Theuns S, Conceição-Neto N, Christiaens I, Zeller M, Desmarets LMB, Roukaerts IDM, et al. Complete genome sequence of a porcine epidemic diarrhea virus from a novel outbreak in Belgium, January 2015. Genome Announc. 2015; 3:e0506-15. http://dx.doi.org/10.1128/genomeA.00506-15

12. Sozzi E, Luppi A, Lelli D, Moreno Martin A, Canelli E, Brocchi E, et al. Comparison of enzyme-linked immunosorbent assay and RTPCR or the detection of porcine epidemic diarrhoea virus. Res Vet Sci. 2010;88:166-8. http://dx.doi.org/10.1016/j.rvsc.2009.05.009

13. Lelli D, Papetti A, Sabelli C, Rosti E, Moreno A, Boniotti MB. Detection of coronaviruses in various bat species in Italy. Viruses. 2013;5:2679-89. http://dx.doi.org/10.3390/v5112679

14. Kim SY, Song DS, Park BK. Differential detection of transmissible gastroenteritis virus and porcine epidemic diarrhea virus by duplex RT-PCR. J Vet Diagn Invest. 2001;13:516-20. http://dx.doi.org/10.1177/104063870101300611

15. Kim L, Chang KO, Sestak K, Parwani A, Saif LJ. Development of a reverse transcription-nested polymerase chain reaction assay for differential diagnosis of transmissible gastroenteritis virus and porcine respiratory coronavirus from feces and nasal swabs of infected pigs. J Vet Diagn Invest. 2000;12:385-8. http://dx.doi.org/ $10.1177 / 104063870001200418$

Address for correspondence: M. Beatrice Boniotti, Research and Development Laboratory, Istituto Zooprofilattico Sperimentale della Lombardia e Emilia Romagna, via Bianchi 9, 25124 Brescia (BS), Italy; email: mariabeatrice.boniotti@izsler.it

\title{
Emerging Infectious Diseases Journal Podcasts
}

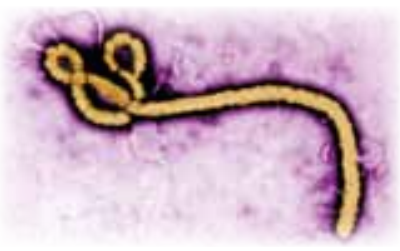

Dr. Mike Miller reads an abridged version of the article, Biomarker Correlates of Survival in Pediatric Patients with Ebola Virus Disease.

\author{
http://www2c.cdc.gov/podcasts/player.asp?f $=8633631$
}

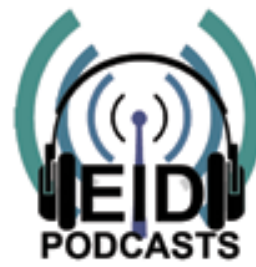

